\title{
ANALISIS FAKTOR YANG MEMPENGARUHI MINAT IBU DALAM PELAKSANAAN PROGRAM LIMA IMUNISASI DASAR LENGKAP DI WILAYAH PUSKESMAS BANGETAYU KOTA SEMARANG
}

\author{
Endang Susilowati ${ }^{1}$ \\ ${ }^{1}$ Prodi D3 Kebidanan Fakultas Kedokteran Unissula
}

Email:esusilowati27@gmail.com

\begin{abstract}
Abstrak
Pemberian Imunisasi Dasar Lengkap (IDL) pada bayi, merupakan suatu keharusan. Hasil survei Riskesdas tahun 2013 didapatkan data cakupan imunisasi HB-0 (79,1\%), BCG (87,6\%), DPT-HB-3 (75,6\%), Polio-4 (77,0\%), dan imunisasi campak (82,1\%). Cakupan imunisasi lengkap di Jawa Tengah pada tahun 2013 mengalami penurunan. Jumlah sasaran bayi pada tahun 2013 adalah 575.011 menurun dibanding tahun 2012 sebanyak 592.712. Dampak dari cakupan imunisasi yang rendah yaitu cukup tingginya proporsi kematian bayi yang disebabkan karena tetanus neonatorum (TN) di Indonesia, meningkatnya angka morbiditas dan mortalitas. Tujuan dari penelitian ini adalah mengetahui faktor-faktor apa yang mempengaruhi minat ibu dalam pelaksanaan program lima imunisasi dasar lengkap di Wilayah Puskesmas Bangetayu Kota Semarang, Jenis penelitian yang digunakan adalah explanatory research, adapun pendekatannya menggunakan rancangan cross sectional. Hasil analisis dengan chi square diperoleh hasil signifikansi $p$ value $=0,000$ pada karakteristik umur, pendidikan dan pengetahuan, karena $p$ value $<0,05$ maka secara statistik ada hubungan yang signifikan antara umur, pendidikan dan pengetahuan ibu dengan minat ibu dalam pelaksanaan lima imunisasi dasar lengkap.
\end{abstract}

Kata Kunci : Minat ; Lima Imunisasi Dasar Lengkap

\section{THE AFFECTING FACTORS OF INTEREST OF MOTHERS TO IMPLEMENT FIVE BASIC IMMUNIZATIONS PROGRAM IN BANGETAYU PUBLIC HEALTH CENTER, SEMARANG DISTRICT}

\begin{abstract}
In the immunization program, the provision of Complete Basic Immunization in infants is a must. The result of Riskesdas survey in 2013 revealed immunization coverage of HB-0 was 79,1\%, BCG was 87,6\%, DPT-HB-3 was $75,6 \%$, Polio-4 was $77,0 \%$, and measles immunization was $82.1 \%$. The coverage of complete immunization in Central Java in 2013 has decreased. The number of targeted infants in 2013 was 575,011, decreased from 592,712 in 2012. The impact of low immunization coverage was the high proportion of infant deaths due to Tetanus Neonatorum (TN) in Indonesia, morbidity and mortality rates among infants also increase. The purpose of this research was to know factors that influence interest of mothers to implement five basic immunization program in Bangetayu Public Health Center, Semarang District. The research type is explanatory research with cross sectional design. The result of analysis with chi square showed $p$ value $=0,000$ on the characteristics of age, education and knowledge. As $\mathrm{p}$ value $<0,05$, therefore there is a significant correlation between age, education and mother knowledge with interest of mother to implement five complete basic immunization.
\end{abstract}

Keywords: Interest; Five Basic Immunizations Program

Jurnal SMART Kebidanan Sekolah Tinggi Ilmu Kesehatan (STIKes) Karya Husada Semarang www.stikesyahoedsmg.ac.id/ojs/index.php/sjkb 


\section{Pendahuluan}

Imunisasi sebagai salah satu pencegahan upaya preventif yang berdampak positif terhadap kesehatan masyarakat harus dilaksanakan secara terus-menerus, menyeluruh, dan sesuai standar sehingga mampu memutus mata rantai penularan penyakit serta menimbulkan/ meningkatkan kekebalan seseorang secara aktif terhadap suatu penyakit (Depkes RI, 2005). Indonesia memiliki cakupan imunisasi lengkap pada tahun 2013 meliputi BCG (105,7\%), DPT1+HB1 (99,93), DPT3+HB3 (98,82\%), Polio 3 (110,9\%) dan Campak (101,6\%). Hal ini mengalami peningkatan bila dibanding tahun 2011 dengan BCG (99,0\%), DPT1+HB1 (99,07\%), DPT3+HB3 (102,08\%), Polio 3 (94.0\%) dan Campak (97,85\%) (Kemenkes RI, 2014).

Berdasarkan hasil Riskesdas tahun 2013 cakupan pemberian imunisasi lengkap sebesar $59,2 \%$, imunisasi tidak lengkap sebesar $32,1 \%$, dan tidak pernah diimunisasi sebesar 8,7\%. Salah satu upaya meningkatkan cakupan imunisasi rutin adalah melalui pelayanan imunisasi yang dilaksanakan oleh bidan, sesuai dengan kewenangannya. Cakupan imunisasi lengkap di Jawa Tengah pada tahun 2013 mengalami penurunan. Jumlah sasaran bayi pada tahun 2013 adalah 575.011 menurun dibanding tahun 2012 sebanyak 592.712. Sedangkan cakupan masing-masing jenis imunisasi tahun 2013 adalah sebagai berikut BCG (100,65\%), DPT1+HB1 (99,93), DPT3+HB3 (99,76\%), Polio 3 (100,69\%) dan Campak (98,24\%). Hal ini mengalami peningkatan bila dibanding tahun 2011 dengan BCG (98,0\%), DPT1+HB1 (97,0\%), DPT3+HB3 (95,7\%), Polio 3 (94.0\%) dan Campak (93,6\%) (Profil Kesehatan Provinsi Jawa Tengah, 2013). Cakupan imunisasi lengkap di Semarang pada tahun 2013 mengalami penurunan dari tahun 2012 masing-masing jenis imunisasi adalah sebagai berikut BCG (117,5\%), DPT1+HB1 (119,8\%), DPT3+HB3 (121,3\%), Polio 3 (120\%) dan Campak $(121,9 \%)$ (Profil Kesehatan Kota Semarang, 2013).

Dampak dari cakupan imunisasi yang rendah yaitu cukup tingginya proporsi kematian bayi yang disebabkan karena tetanus neonatorum (TN) di Indonesia (Marimbi, 2010, hal: 111), meningkatnya angka morbiditas dan mortalitas (Proverawati \& Andhini, 2010. Hal: 5). Upaya dalam mencapai target imunisasi dasar lengkap pada bayi antara lain: semua Puskesmas membuat Pemantauan Wilayah Setempat (PWS) imunisasi secara rutin (bulanan, tribulanan), dilakukan pelaksanaan sweeping atau kunjungan rumah untuk melengkapi status imunisasi pada daerah-daerah yang cakupan imunisasinya masih rendah dan memberikan informasi pada sebagian kecil orang tua yang menolak anaknya untuk diimunisasi dikarenakan keyakinan/kepercayaan agama, dan lain-lain (Profil Kesehatan Provinsi Jawa Tengah, 2012). Jurnal SMART Kebidanan Sekolah Tinggi Ilmu Kesehatan (STIKes) Karya Husada Semarang www.stikesyahoedsmg.ac.id/ojs/index.php/sjkb 
Oleh karena itu minat merupakan aspek psikis yang dimiliki seseorang yang menimbulkan rasa suka atau tertarik terhadap sesuatu. Minat juga mempunyai hubungan yang erat dengan dorongan dalam diri individu yang kemudian menimbulkan keinginan untuk berpartisipasi atau terlibat pada suatu yan diminatinya. Seseorang yang berminat pada suatu objek maka akan merasa senang bila berkecimpung didalam objek tersebut sehingga cenderung akan memperhatikan terhadap objek. (Djaali, 2007). Cakupan LIL di 2 Puskesmas yaitu Puskesmas Genuk dan Bangetayu tidak ada yang mencapai 100\% pada tahun 2013 dan 2014. Kisaran 7890 \% pada tahun 2013 dan 76-93\% tahun 2014 di Puskesmas Genuk dimana prosentase paling rendah adalah imunisasi Campak. Sedangkan di Puskesmas Bangetayu kisaran 46-82 \% tahun 2013 dan 48-79\% pada tahun 2014 terendah adalah imunisasi HB0.

\section{Tinjauan Teoritis}

\section{A. Minat}

1. Pengertian

Minat sebagai suatu kecenderungan atau keinginan yang tinggi terhadap sesuatu. Minat menjadikan seseorang untuk mencoba dan menekuni suatu hal dan pada akhirnya diperoleh pengetahuan yang lebih mendalam (Syah, 2013)

2. Faktor-faktor Yang Mempengaruhi Perubahan Minat
a. Usia
b. Kesehatan
c. Status Ekonomi
d. Pendidikan
e. Perubahan Dalam Nilai
f. Pengetahuan
g. Sikap Keluarga

3. Alat Ukur Minat

Menurut Makmun (2012) alat ukur kepribadian yang berkenaan dengan minat (interest) dapat dijabarkan menjadi enam minat yaitu :

a. Teoritis (theoritical) ditandai dengan minatnya dominan untuk menemukan kebenaran dengan pendekatan empiris, kritis, rasional dan intelektual.

b. Ekonomis (economical) ditandai dengan minat yang mengutamakan nilai kegunaan dan kepraktisan. 
c. Estetis (aesthetical) ditandai dengan menempatkan nilai tertinggi pada bentuk keharmonisan, serasi dan simetris.

d. Sosial (social) ditandai dengan mengutamakan nilai kebersamaan, kemanfaatan dan kebaikan sesama manusia, solidaritas dan filantropis.

e. Politis (political) ditandai dengan minat yang dominan untuk kepentingan pengaruh dan kekuatan pribadi dan ketenaran dirinya.

f. Religius (religious) sangat berkepentingan dengan kenyataan kesatuan pengalaman secara keseluruhan dalam kaitannya dengan alam semesta dan Maha Pencipta.

4. Pengukuran Minat

Minat diukur dengan menggunakan kuesioner atau dengan menggunakan wawancara.

Dalam TRA (Theory of Reasoned Action). Minat merupakan bagian dari intense sehingga belum nampak kegiatannya dan tidak dapat dilakukan observasi secara langsung.

Adapun hasil pengukuran minat ada 3 (Nursalam, 2008):

a. Rendah jika seseorang tidak menginginkan objek minat, dan jika dari $100 \%$ pertanyaan, jawaban yang dijawab benar 0-33\%.

b. Sedang jika seseorang menginginkan objek minat akan tetapi dalam waktu segera dan jika dari $100 \%$ pertanyaan, jawaban yang dijawab benar 34-66\%.

c. Baik jika seseorang sangat menginginkan objek minat dalam waktu segera dan jika dari $100 \%$ pertanyaan yang dijawab benar $67-10 \%$.

\section{B. Imunisasi}

1. Pengertian

Imunisasi adalah usaha untuk memberikan kekebalan pada bayi dan anak dengan memasukkan vaksin ke dalam tubuh agar tubuh membuat zat anti, untuk mencegah timbulnya penyakit tertentu (Hidayat, 2007. Hal: 60). Imunisasi ialah pemberian vaksin kepada seseorang untuk melindunginya dari beberapa penyakit tertentu. (Marimbi, 2010. Hal: 110).

2. Tujuan

Program imunisasi bertujuan untuk memberikan kekebalan kepada bayi agar dapat mencegah penyakit dan kematian bayi serta anak yang disebabkan oleh penyakit yang sering berjangkit. 
3. Manfaat

a. Untuk anak: mencegah penderitaan yang disebabkan oleh penyakit, dan kemungkinan cacat atau kematian

b. Untuk keluarga: menghilangkan kecemasan dan psikologi pengobatan bila anak sakit. Mendorong pembentukan keluarga apabila orang tua yakin bahwa anaknya akan menjalani masa kanak-kanak yang nyaman

c. Untuk negara: memperbaiki tingkat kesehatan, menciptakan bangsa yang kuat dan berakal untuk melanjutkan pembangunan negara (Marimbi, 2010. Hal: 112).

4. Imunisasi yang wajib diberikan

a. Imunisasi BCG (Bacillus Celmette-Geurin)

b. Imunisasi DPT (Difteri, Pertusis, dan Tetanus)

c. Imunisasi Hepatitis B

d. Imunisasi Polio

e. Imunisasi Campak

\section{Metode Penelitian}

Jenis penelitian yang digunakan adalah explanatory research, pendekatannya menggunakan rancangan cross sectional, Populasi target dalam penelitian ini adalah seluruh ibu menyusui yang mempunyai bayi usia 0-12 bulan di Wilayah Puskesmas Banget Ayu yang berjumlah 81 orang sedangkan Teknik sampling dengan metode accidental sampling, dimana sampel dikumpulkan sampai memenuhi besar sampel sejumlah 50 sampel dengan rumus Solvin. Penelitian dilaksanakan di Wilayah Puskesmas Banget Ayu Kota Semarang sejak bulan September sampai dengan Desember 2016. Instrument yang digunakan yaitu kuesioner. Untuk mengetahui adanya korelasi, analisa data dengan menggunakan rumus Rank Spearman.

\section{Hasil Penelitian}

Karakteristik usia Responden $44 \%$ dalam kategori Remaja awal, 44\% Dewasa awal dan $12 \%$ Dewasa Akhir, karakteristik berdasarkan pendidikan mayoritas responden mempunyai tingkat pendidikan SMP yaitu $38 \%$, paritas mayoritas responden dalam kategori multigravida yaitu $40 \%$, sedangkan berdasarkan pengetahuan mayoritas responden mempunyai pengetahuan baik yaitu $50 \%$. 
Tabel 1 Tabel Silang Umur dengan Minat Ibu Dalam Pelaksanaan Lima Imunisasi Dasar Lengkap DiWilayah Puskesmas Bangetayu

\begin{tabular}{|c|c|c|c|c|c|c|}
\hline \multirow{2}{*}{ Usia } & \multicolumn{4}{|c|}{ Minat } & \multirow{2}{*}{ Jumlah } & \multirow{2}{*}{$p$ Value } \\
\hline & Minat & $\%$ & Tidak Minat & $\%$ & & \\
\hline Remaja Akhir & 5 & 10 & 17 & 34 & 22 & \\
\hline Dewasa Awal & 17 & 34 & 5 & 10 & 22 & 0.000 \\
\hline Dewasa Akhir & 6 & 12 & 0 & 0 & 6 & \\
\hline Jumlah & 28 & 56 & 22 & 44 & 50 & \\
\hline
\end{tabular}

Tabel 2 Tabel Silang Pendidikan dengan Minat Ibu Dalam Pelaksanaan Lima Imunisasi Dasar Lengkap DiWilayah Puskesmas Bangetayu

\begin{tabular}{lcccccc}
\hline \multirow{2}{*}{ Pendidikan } & Minat & $\%$ & Tidak Minat & $\%$ & Jumlah & $p$ Value \\
\hline SD & 2 & 4 & 11 & 22 & 13 & \\
SMP & 11 & 22 & 8 & 16 & 19 & \\
SMA & 9 & 18 & 3 & 6 & 12 & 0.000 \\
PT & 6 & 12 & 0 & 0 & 6 & \\
\hline Jumlah & 28 & 56 & 22 & 44 & 50 & \\
\hline
\end{tabular}

Tabel 3 Tabel Silang Paritas dengan Minat Ibu Dalam Pelaksanaan Lima Imunisasi Dasar Lengkap DiWilayah Puskesmas Bangetayu

\begin{tabular}{lcccccc}
\hline \multirow{2}{*}{ Pendidikan } & Minat & $\%$ & $\begin{array}{c}\text { Minat } \\
\text { Tidak Minat }\end{array}$ & $\%$ & Jumlah & $p$ Value \\
\hline Primigravida & 6 & 12 & 6 & 12 & 12 & \\
Multigravida & 13 & 26 & 7 & 14 & 20 & 0.853 \\
Grandemulti & 9 & 18 & 9 & 18 & 18 & \\
\hline Jumlah & 28 & 56 & 22 & 44 & 50 & \\
\hline
\end{tabular}

Tabel 4 Tabel Silang Pengetahuan dengan Minat Ibu Dalam Pelaksanaan Lima munisasi Dasar Lengkap DiWilayah Puskesmas Bangetayu

\begin{tabular}{lcccccc}
\hline \multirow{2}{*}{ Pengetahuan } & Minat & $\%$ & Tidak Minat & $\%$ & Jumlah & $p$ Value \\
& 22 & 44 & 3 & 6 & 25 & \\
Baik & 6 & 12 & 7 & 14 & 13 & 0.000 \\
Cukup & 0 & 0 & 12 & 24 & 12 & \\
Kurang & 28 & 56 & 22 & 44 & 50 & \\
\hline Jumlah & & & & &
\end{tabular}

Berdasarkan Tabel diatas dapat diketahui bahwa 17 (34\%) responden dalam kategori dewasa awal mempunyai minat dalam pelaksanaan lima imunisasi dasar lengkap, sedangkan yang tidak mempunyai minat mayoritas dalam kategori usia remaja akhir yaitu sebanyak 17 (34\%), tingkat pendidikan SMP mempunyai minat yang baik yaitu 11 (22\%), sedangkan sebanyak 11 (22\%) Jurnal SMART Kebidanan Sekolah Tinggi Ilmu Kesehatan (STIKes) Karya Husada Semarang www.stikesyahoedsmg.ac.id/ojs/index.php/sjkb 
pendidikannya SD dan tidak minat, responden yang dalam kategori multigravida mempunyai minat yang baik yaitu 13 (26\%) dan 9 (18\%) responden dengan kategori grandemulti tidak minat, kategori ibu dengan pengetahuan baik mempunyai minat yang baik pula yaitu 22 (44\%), sedangkan kategori ibu dengan pengetahuan kurang juga mempunyai minat yang kurang juga yaitu $12(24 \%)$.

\section{Pembahasan}

Hasil penelitian menunjukkan bahwa responden yang mempunyai minat dalam pelaksanaan lima imunisasi dasar lengkap termasuk dalam kategori dewasa awal, tingkat pendidikan SMP, dan pengetahuan yang baik, hal ini sesuai dengan hasil analisis dimana chi square $p$ value $=0,000$, karena $p$ value $<0,05$ maka secara statistik ada hubungan yang signifikan antara dua variabel. Usia sangat berkaitan dengan minat karena minat seseorang akan berubah seiring dengan bertambahnya kedewasaan seseorang. Dalam masa dewasa seseorang cenderung diwarnai oleh minat yang berorientasi masa depan Hurlock, (2002).

Umur memengaruhi seseorang dalam bersikap dimana seseorang yang lebih dewasa akan lebih matang dalam berfikir. Ibu bayi dengan pendidikan menengah pertama dan sekolah dasar sebenarnya masih termasuk dalam kategori pendidikan dasar. Dimana seorang ibu yang berpendidikan dasar biasanya memiliki akses untuk mendapatkan informasi yang lebih sedikit sehingga akan memengaruhi pula terhadap perubahan minat dibandingkan dengan ibu yang berpendidikan menengah keatas atau yang lebih tinggi. Tetapi tidak bisa kita pungkiri bahwa dengan semakin berkembangnya ilmu dan teknologi yang bisa dijangkau oleh siapa saja, maka ibu yang tidak berpendidikan juga bisa mencari informasi melalui media sosial, sehingga dengan hal tersebut bisa merubah minat dan perilaku ibu. Makin tinggi tingkat pendidikan seseorang makin baik minat seseorang terhadap pengetahuan yang baru. Sebaliknya pendidikan yang kurang akan mempengaruhi perkembangan minat seseorang nilai-nilai yang baru.

Sesuai dengan penelitian Latifah, (2010) yang menyatakan ada hubungan antara tingkat pengetahuan ibu tentang imunisasi dasar dengan pemberian imunisasi dasar. Dari hasil perhitungan $\mathrm{x}^{2}$ didapatkan koefisien cotingency 0.243 yang menunjukkan besarnya hubungan antara tingkat pengetahuan ibu dengan pemberian imunisasi dasar pada balita. Minat akan timbul dari sesuatu yang telah diketahui dan kita dapat mengetahui sesuatu melalui belajar. 
Hurlock (2002). Semakin tinggi pengetahuan seseorang tentang kesehatan maka semakin baik minat seseorang terhadap kesehatan. Hasil penelitian Dewi (2013) juga menyatakan Adanya hubungan yang bermakna antara pengetahuan ibu dengan pemberian imunisasi dasar lengkap pada bayi di kelurahan Parupuk Tabing Kota Padang.

\section{Kesimpulan}

Ada hubungan yang signifikan antara umur, pendidikan ibu, pengetahuan ibu dengan minat ibu dalam pelaksanaan lima imunisasi dasar lengkap.

\section{Saran}

Bagi masyarakat agar membawa bayi ke fasilitas kesehatan untuk mendapatkan imunisasi lengkap dan berkunjung ke Puskesmas atau Posyandu untuk mendapatkan informasi tentang kesehatan terutama kesehatan yang berkaitan dengan bayi. Bagi petugas kesehatan dapat mensosialisasikan ke masyarakat tentang program imunisasi dasar lengkap dan memberikan leaflet tentang lima imunisasi dasar lengkap kepada ibu yang mempunyai bayi serta memasang poster lima imunisasi dasar lengkap di Posyandu. Bagi peneliti selanjutnya lebih inovatif dalam melakukan penelitian, lebih mendalam tentang imunisasi pada bayi, tidak sebatas pada faktor minat saja.

\section{Daftar Pustaka}

A.Alimul Hidayat. (2007). Metode Penelitian Kebidanan Dan Tehnik Analisis Data. Surabaya: Salemba.

Abin Syamsuddin Makmun dan Yunus. (2012). Psikologi Pendidikan. PT Rosda Karya Remaja. Bandung.

Badan Penelitian Dan Pengembangan Kesehatan Kementerian Kesehatan RI. (2013). Riset Kesehatan Dasar Tahun 2013. Jakarta.

Dewi.P.A.dkk (2013). Hubungan Tingkat Pengetahuan Ibu dengan Pemberian Imunisasi Dasar Lengkap pada Bayi di Kelurahan Parupuk Tabing Wilayah Kerja Puskesmas Lubuk Buaya Kota Padang Tahun 2013. http://jurnal.fk.unand.ac.id

Dinkes, Prov, Jateng. (2013). Profil Kesehatan Kota Semarang. Semarang.

Dinkes, Prov, Jateng. (2013). Profil Kesehatan Jawa Tengah. Semarang.

Kemenkes, RI. (2014). Profil Kesehatan Indonesia Tahun 2013. Jakarta.

Jurnal SMART Kebidanan Sekolah Tinggi Ilmu Kesehatan (STIKes) Karya Husada Semarang www.stikesyahoedsmg.ac.id/ojs/index.php/sjkb 
Latifah Ulfatul. (2010). Hubungan Pengetahuan Ibu Tentang Imunisasi Dasar Dengan Pemberian Imunisasi Dasar Pada Anak Balita Di Kelurahan Pesurungan Kidul Kota Tegal. (Journal Research Midwifery Politeknik, 2014 - ejournal.poltektegal.ac.id).

Marimbi . (2010). Tumbuh Kembang, Status Gizi dan Imunisasi Dasar pada Balita. Yogyakarta : Nuha Medika.

Notoatmodjo,Soekidjo. (2005). Metodologi Penelitian Kesehatan. Jakarta : PT. Rineka Cipta.Nursalam. (2008). Konsep dan penerapan metodologi penelitian keperawatan. Jakarta.

Proverawati,A dan Andhini,D.S.C. (2010). Imunisasi dan Vaksinasi. Yogyakarta : Nuha Medika. 